\title{
CONTEXTO, LEITURA E SUBJETIVIDADE
}

\section{CONTEXT, READING AND SUBJECTIVITY}

\author{
Lígia Maria Moreira DUMONT'
}

\section{RESUMO}

Os estudos da efetivação do ato da leitura tecem suas raizes principalmente em três dimensões: o contexto, a motivação e o sentido. Os conceitos, advindos em primeira instância da história, da psicologia e da semiologia, respectivamente, demonstram o imbricado de assuntos e áreas do conhecimento que necessitam ser analisados para obter-se a compreensão da verdadeira efetivação da leitura. Apesar da fusão desses três conceitos atuarem quase indistintamente na prática da leitura, o artigo detém-se, de forma didática, na dimensão contexto. É considerado como o elemento catalisador da leitura, pois se o contex to descrito pelo autor não for ao encontro com o do leitor, não bater com a sua vivência, a ação leitura não se efetivará. São apresentados argumentos de pensadores da área de leitura, destacando conceitos, teses e postulados por eles elaborados.

Palavras-chave: leitura e contexto-leitura e subjetividade.

\section{ABSTRACT}

The studies about the effectiveness of the act of reading weave their roots mainly in three dimensions: context, motivation and meaning. These concepts came from history, psychology and semiology, respectively, demonstrating an imbrication of knowledge areas that need to be analyzed to achieve the understanding of the true reading effectiveness. Despite the fact that these these concepts act almost indistinctly in the practice of reading, the article focuses the context in a didactic way. It is considered a reading catalysis element, because if the context described by the author doesn't coincide with the reader's context, his existence, the reading will not be accomplished. Reading philosophers' arguments and discussions are presented, emphasizing their concepts and theses.

Key-words: reading and context - reading and subjectivity

\section{INTRODUÇÃO}

O comando da leitura se dá a partir de temas significativos, segundo a experiência do leitor - e não a do autor. A verdadeira efetivação da leitura, como da alfabetização, necessita partir de um atrativo, algo familiar, para se chegar à decodificação dos sinais alfabéticos e, conseqüentemente, à compreensão do

\footnotetext{
(1) Professora adjunta da Escola de Ciência da Informação da UFMG. Doutora em Comunicação c Cultura. dumont@eci.ufmg.br
} 
texto. Assim, o leitor será capaz de fazer uma interpretação global da escrita, que será finalmente percebida como algo que vai ao encontro de seu interesse, de sua vivência ou pelo contrário, não Ihe desperta a atenção. Dentre os vários conceitos que compõem o estudo da leitura, cabe destacar os de contexto, sentido e motivação advindos, em primeira instãncia, da sociologia, da semiologia e da psicologia, respectivamente e que se imbricam fortemente. Embora os três conceitos na prática do ato da leitura se fundam em quase um só, este artigo limita-se a destacar a função do contexto do leitor nas práticas de decodificação do contexto do autor. Certamente, dentre os conceitos de interesse para a área, o que possui noção mais abrangente é o de contexto.

\section{CONTEXTUALIZANDO A LEITURA E O SUJEITO}

Não se trata de estudar as leituras realmente praticadas de uma obra, ou de outra, em determinada época, ou em outra. Trata-se sim de examinar como um texto se expõe, explicitamente ou não, à leitura, ou às leituras que são feitas ou podem ser feitas, como se permite a liberdade de leitura, ou se faz sua restrição, a partir da vivência do leitor. A compreensão de um texto, a ser efetivada pela leitura crítica, enreda-se na percepção das relações entre o texto e o contexto.

As implicações do contexto onde se produz uma ação e onde se produz um texto, ou mesmo uma obra de arte, um discurso, uma teoria, enfim, onde e quando qualquer produção ou ação humana se efetiva, devem constituir o primeiro acesso para se interpretar e entender qualquer manifestação de um sujeito, ou de uma coletividade. Na ação da leitura e na formação de um autor e de um leitor, existe sempre uma dimensão comunitária que, em princípio, imprime nesses atores valores decorrentes da comunidade.

Para se introduzir o assunto, toma-se como exemplo a produção literária, considerada a forma mais elaborada de se redigir textos. Um texto clássico de CÂNDIDO (1976), que explicita as implicações entre teoria da literatura e sociologia, deixa clara a importância que se deve dar aos fatores sociológicos na análise literária, pois há uma relação intrínseca entre a produção e a sociedade do autor. A relação consiste em exprimir os traços dessa sociedade, onde os escritos do autor representam a realidade exterior. Mas esse pode se organizar num sistema diferente da realidade, com possibilidades combinatórias mais limitadas, porém sempre dependentes dessa realidade.

Antônio Cândido resume sua proposição teórica, explicando que existe na criação do texto certa "deformação criadora", devido à tensão entre o desejo de reproduzir e o de inventar. A deformação depende da diferença entre a intenção do autor e a atuação de forças mais fortes do que ele, que motiva a constituição de um subsolo debaixo da camada aparente de significado. Essas forças se prendem às estruturas mentais dos grupos e classes sociais a que o autor pertence, e que se caracterizam por um certo modo de ver o mundo. O elemento individual, segundo o autor, puxa a "expressão estética para um lado, e o social para outro, sendo este o significado profundo". Então, o texto se diversifica verticalmente, aprofunda-se, obrigando o analista a complementar a análise estética com a sociológica. A camada estética do texto aparece na superfície de sua organização formal e é esta que comanda o trabalho analítico sobre a camada profunda, "que só se configura e a esclarece no jogo de ir e vir entre as duas camadas". Para melhor entender o postulado de que é necessário contextualizar-se qualquer ação humana, é preciso esclarecer que o texto acima referenciado foi apresentado em meados da década de 70 , em congresso, para contrapor-se à onda estruturalista vigente, provocando uma forte reação na medida em que procurou compatibilizar a idéia de autonomia do texto literário com uma sociologia que, mesmo fazendo concessões à moda, enraíza o texto no social ou seja, no contexto.

Também OLSEN (1979) afirma que a teoria estruturalista da linguagem não oferece uma base aceitável, porque a obra literária, como um tipo peculiar de enunciado, não pode ser interpretada sem referência a algum contexto, ou ambiente. Interpretar um texto como obra literária significa, entre outras coisas, estar disposto a supor que um pequeno detalhe tenha um significado intencional. A diferença entre uma frase usada como afirmação real e a mesma frase usada como imitação de afirmação numa obra literária, para caracterizar uma personagem, não se reflete apenas nos seus aspectos sintáticos. A diferença é uma questão de contexto, mais especificamente, uma questão do objetivo que o leitor atribui ao enunciado. Com isso o autor quer dizer que se um texto literário é essencialmente um discurso, e todo discurso é intencional, então o objetivo de um texto se pode explicar como uma tentativa de modificar as convicções ou perspectivas do leitor, a partir da leitura que ele faz do texto dentro de um contexto. A tentativa do autor é válida, presente, mas o que não significa que o leitor vai lê-la sem a sua interpretação, seu contexto.

Sob essa ótica, pode-se entender porque Balzac possui uma obra inteiramente humanizada, onde o homem é o centro e, como conseqüência, o leitor 
sente-se prontamente envolvido, sem perceber se foi realmente a intenção original do autor, ao esmerar na riqueza de detalhes das descrições. Essas, baseiamse na idéia de ser impossivel contemplar um universo em si mesmo, como se o leitor nada tivesse a ver com ele em nenhum momento, nem nos menores detalhes da vida cotidiana.

\section{A LEITURA DE MASSA}

Quanto à tendência, dominante, em trabalhos publicados até o final da década de 70, de considerar a literatura de massa como transmissora das ideologias reformistas do poder, as afirmações não conseguem, não chegam a comprovar, com certeza, o efeito que o romance produz. Com isso, acaba-se comprovando o contrário, este sim, tendo consenso: ainda não se pode afirmar com certeza os efeitos ocasionados pela leitura. Chega-se a essa constatação pela incoerência de autores renomados afirmarem que os romances privilegiam o conservadorismo, enquanto outros, também renomados, confirmam que os mesmos tiveram um papel importante na construção da consciência operária. Balzac é tido como um escritor conservador, mas é citado por Lukàcs e Gramsci, por discorrer com primor sobre a sociedade burguesa. Eugène Sue era dândi, mas se sensibilizava ao escrever e trocar experiências com os seus leitores advindos da classe operária e se tornou deputado socialista; no entanto, foi rechaçado por Marx.

Poder-se-ia também citar como exemplo a trajetória das idéias transmitidas pela obra de Umberto Eco, onde se nota uma mudança, refletida no abrandamento da crítica às publicações populares. Em Seis passeios pelos bosques da ficção (1994), Eco publica palestras que giram em torno de uma crítica bem mais suave sobre essas publicações, do que em relação a Apocalípticos e integrados (c1977) e O Super Homem de massa (c1978), por exemplo. É verdade que Eco nunca deixou de demonstrar um certo fascínio ao discorrer sobre os textos que encantam o imaginário dos leitores de romances populares. Crítico do mito transmitido pelos heróis, no romance $\mathrm{O}$ nome da rosa cria uma personagem que deslinda todos os mistérios, no mais refinado estilo sherloquiano, protagonizado, no cinema, pelo artista que encarna o mitológico Agente 007, Sean Connery.

\section{A LEITURA ENGAJADA}

Ao contrário do que se imaginava, a descrição formal tende a atrair a atenção do leitor, explica PINGAUD (1968). Ao priorizar detalhes que 'podiam' extraviar a atenção, nuanças que a princípio não teriam valor significativo no desenrolar do relato, proporcionam, na verdade, um comprometimento do homem com o mundo, onde pequenos detalhes podem oferecer grandes reflexões. As personagens ficam ao nível do 'seria', não são reais, e sim fictícias. Já a descrição 'anuncia, denota, mostra, testemunha'; em uma palavra, já é uma realidade que o leitor descobrirá.

Há uma corrente de críticos literários que alertam para a tendência de, incorrendo-se em exageros, inverter a ordem, ou seja, tomar a arte como reprodução do real, como produto e não como produção. MALARD (1995) cita a Teoria do reflexo, de Lenin ${ }^{2}$, onde se verifica um esforço para dar à arte literária um conteúdo filosófico (Teoria do conhecimento) acrescido do literário (artigos sobre Tolstói). Lenin insere o texto num contexto mais vasto, como por exemplo no artigo de Tolstói, Espelho da revolução russa, que tem como pano de fundo o princípio estabelecido por Marx, de que não é a consciência dos homens que determina sua existência, mas a existência social que determina a consciência. FOX (1937) acrescenta que nos textos produzidos nessa época se percebe um esforço leniniano de dar grande ênfase ao conteúdo político engajado, fundamentado, é claro, no princípio básico do marxismo, de que as idéias não são agentes independentes da história.

$\mathrm{Na}$ década de 60 , Lukàcs ${ }^{3}$ dá continuidade e aperfeiçoa a teoria de Lenin através da teoria intitulada Visão do mundo. Estuda o grande realismo de Balzac e o caráter conservador, pequeno-burguês de Zola. Analisa conteúdos de obras diversas, afastando-se de uma sociologia vulgar e identificando o valor revolucionário dessas obras na soma de suas idéias progressistas. A ideologia de Lukàcs trabalha nos limites da visão-de-mundo e da consciência mistificadora. A obra é produto de uma classe e tem que se situar diante de outras concepções de mundo. A crítica que Malard faz às teorias da linha marxista, é de que essas praticamente ignoram os fatores que caracterizam o texto como obra de arte de linguagem. A literatura é vista como um universo de bons e maus conteúdos.

No outro extremo, em substituição às análises que enfatizam categorias ortodoxas do marxismo,

\footnotetext{
(2) Malard esclarece que os principios da Teoria do reflexo foram estabelecidos em vários textos escritos por Lenin no periodo de 1900 a 1959.

(3) LUKÀCS, Gyorgy. Ensaios sobre literatura. Rio de Janeiro: Civilização Brasileira,1965.
} 
passa-se da totalidade à fragmentação. Ainda segundo MALARD (1995),

\begin{abstract}
"conquistas sociais primárias foram e continuam sendo perdidas, em nome de novos valores do individualismo consumista verificado nas sociedades neoliberais. Desde o advento da indústria cultural, onde se visa primordialmente o lucro, mascara-se em direitos de minorias, bandidagem, ecologia, alteridades, câmaras setoriais, excluídos. Às vezes a literatura tem tratado disso. E a análise/crítica literária?" (p.3)
\end{abstract}

\section{A CRÍTICA LITERÁRIA E A EXCLUSĀO}

A crítica literária desenvolve-se analítica e criticamente por dois segmentos: os críticos especializados e os amadores. É comum um determinado escritor ser admirado pelo público leitor em geral e severamente massacrado pela crítica especializada. Torna-se necessário respeitar o gosto do primeiro segmento, que não possui conhecimentos técnicos para desenvolver uma crítica mais apurada, profunda. É através do exercício da leitura, efetivada paulatinamente de forma democrática e cada vez mais crítica e plural, podendo ser auxiliada por especialistas, que se adquire essa habilidade, e não através da simples imposição. Também não significa que, apesar da diferença, um segmento seja melhor do que o outro.

MOISÉS (1996); lembra que, ainda que os especialistas costumem se referir ao leitor, no singular, como se fosse uma entidade unívoca e homogênea, existe uma diversidade de leitores, assim como uma multiplicidade de literaturas, e a crítica existe para distingui-las como literaturas, bem como para distinguilos enquanto leitores, da mesma forma que a própria crítica é múltipla e plural. A função da crítica, escreve ainda Moisés, talvez não consista em passar ao leitor um julgamento, mas uma atitude crítica capaz de conduzir a julgamentos, colaborando para a formação do gosto pessoal do leitor e não para submetê-lo ao seu próprio gosto.

A indústria cultural edita as publicações e as faz circular, atingir o público consumido. Isso não quer dizer que os livros, revistas, jornais, bem como outros tipos de suportes que viabilizam toda manifestação artística, possam transformar-se em produto de consumo. Graças à pluralidade da criação artística, somada aos fatores de diversidade dos segmentos sociais que a criam, de subjetividade do sujeito que a produz e de diversidade de gosto do sujeito que a aprecia ou não, preserva-se o caráter plural da arte. Com a característica de ser inerentemente inovadora, singular, não é possível encapsular toda manifestação artística dentro de um produto massificador, repetitivo, que é o oferecido à sociedade de consumo.

\section{A CAPACIDADE DE TRANSCENDÊNCIA DO TEXTO}

Outra característica da leitura do texto, fora do contexto do autor é seu anacronismo. Tomando como exemplo os clássicos gregos, definitivamente a leitura não se efetivará com a mesma visão da população grega daquela época, explica BORNHEIM 1994). Hoje, faz-se uma nova leitura, uma espécie de reinterpretação.Por exemplo, atualmente, Édipo Rei tem toda uma interpretação psicológica, freudiana enquanto que na Grécia da sua época, a perspectiva se direcionava para uma tragédia política. Isso não quer dizer que a obra perca o interesse, não instigue mais a leitura porque ficou ultrapassada; pelo contrário, no atual contexto, adquire novas dimensões, interesses; é uma releitura que pode estimular a curiosidade e a crítica do leitor.

A partir dessas proposições, pode-se dizer que o texto literário é metalingüístico, ao

..."apontar para as articulações que mantém, enquanto sistema aberto de significações, com o aparato cultural que o sustenta, viabiliza, interpreta e contextualiza. Noutra formulação: cada texto não apenas representa sua poética, mas também ao mesmo tempo delineia e instiga certos modos de recepção e de leitura antecipando e orquestrando, rompendo e/ou contradizendo suas possibilidades de diálogo com a sociedade." (LAJOLO e ZILBERMAN, 1991,p.8)

O conceito de transcendência do texto abre várias possibilidades para o seu uso e interpretação. Ler é como montar um mosaico, tecer uma trama com fios. As metáforas, muito utilizadas por autores da área de leitura, mostram como o texto torna-se polissêmico ao 'dialogar' com as esferas social e literária em que se insere, permitindo várias leituras. Propicia assim um intercâmbio, um diálogo com as mais diferentes esferas do saber, multidisciplinaridade hoje enfatizada pelas tendências do estudo da literatura, da semiologia, dos estudos dos leitores e, consseqiüentemente da crítica. A multidisciplinaridade só tem significado na medida em que se instaura, a partir dela, uma reflexão crítica sobre os atores, para a produção da literatura, enfim, sobre a cultura como um todo. 


\section{CONCLUSÃO}

Pode-se afirmar que o conceito mais importante que se enlaça fortemente com o de contexto é o de subjetividade. $\mathrm{O}$ contexto tende a igualar as pessoas de uma determinada sociedade, enquanto a subjetividade as diversifica. Pertencer a uma determinada coletividade, ou mesmo ter o real sentimento de pertencer a ela, não oblitera as diferenças de sensibilidade, de sistemas de valores e de sentimentos do sujeito. A simples conversa com alguns sujeitos pertencentes a determinada coletividade mostra, sem grandes dificuldades, que eles fazem parte de 'outros grupos' que não são aqueles da escola e da igreja que freqüentam, da família, do bairro, da associação esportiva ...Todos esses lugares sociais contribuem para formar suas personalidades e produzem a parte que compreende o arcabouço de cada indivíduo. Todavia, os determinismos de integração social não produzem necessariamente o homogêneo, pois o indivíduo tem alguma coisa própria, individual, uma variação. um desvio, uma 'falha' dentro do sistema em que ele se insere. Constata-se aqui a existência de uma autêntica diferença, que se forma através do sentido que o sujeito dá à ação. E esse sentido é que diferencia um sujeito de todos os outros - é a chamada subjetividade.

Os paradigmas da leitura, válidos para uma comunidade de leitores, num momento e num lugar determinados, comportam modos específicos. A sua caracterização é, portanto, indispensável a toda abordagem que vise reconstituir o modo como os textos podem ser apreendidos. Torna-se imprescindível lembrar que essas singularidades não advêm necessariamente de uma homogeneidade: são pessoas bem diferentes e que se assemelham porque são obrigadas a pertencer a uma classe. Pode-se tomar como exemplo as classes socio-economicamente carentes da periferia de grandes centros urbanos que, obrigatoriamente, se assemelham por várias características: o fracasso escolar, a indiferença que o sistema manifesta por seus anseios, seus gostos, o reagrupamento forçado em locais e casas de pouca infra-estrutura, ou mesmo conjuntos habitacionais idênticos, perspectivas de vida fluidas e sombrias, etc., etc. Porém, o real sentimento de pertencer a uma comunidade - os companheiros, a cidade, a turma - não destrói, não elimina as diferenças de sensibilidade, de sistema de valores.

Ao afirmar que a literatura é um processo de descontextualizar a pessoa, QUEIRÓS (1994) cria uma certa polêmica. Mas na realidade, o que ele traduz por descontextualizar a pessoa, no caso o leitor, possui o mesmo sentido até então explicitado por outros autores: a literatura tem que criar desequilíbrios no sujeito, desestabilizar; em outras palavras, propiciar a reflexão. "Se o texto não me desequilibra um pouco, se ele não me convida, se não me abre uma porta, eu acho que não é literário. É como um escancarar as coisas, e a paisagem é do sujeito, está no olho dele, ele é que vai projetar isso" (p.155). O sentido criado à primeira vista - contrário ao que foi até então proposto - de que o autor está advogando a não contextualização do texto, mais uma vez só prova que as palavras podem produzir sentidos completamente diversos, se não forem 'contextualizadas' com muita clareza; principalmente se vierem da fala de um escritor poeta.

\section{REFERÊNCIAS BIBLIOGRÁFICAS}

1 BORNHEIM, Gerd. Resposta à mesa-redonda. In: SANTOS, Wanderley Guilherme dos (Debat.). SIMPÓSIO NACIONAL DE LEITURA, Rio de Janeiro, 1994. Leitura, saber e cidadania. Rio de Janeiro: Fundação Biblioteca Nacional,1994. p.36.

2 CÂNDIDO, Antônio. O discurso e a cidade. 4.ed. São Paulo: Duas Cidades, 1993. p.123-152: De cortiço a cortiço.

3 FOX, Ralph. The novel and the psople. London: Lawrence and Wishart, 1937.

4 LAJOLO, Marisa, ZILBERMAN, Regina. A leitura rarefeita: livro e literatura no Brasil. São Paulo: Brasiliense, 1991

5 MALARD, Letícia. Teoria da literatura e sociologia: o discurso marxista na análise literária. Belo Horizonte: Faculdade de Letras da UFMG, 1995. (Resumo de palestra, texto digitalizado).

6 MOISÉS, Sarita Maria Affonso. Literatura e história: imagens de leitura e de leitores no Brasil no século XIX. Revista Brasileira de Educação, São Paulo, n.0, p.53-62, set./dez.1995.

7 OLSEN, Stein Haugom. A estrutura do entendimento literário. Rio de Janeiro: Zahar,1979.

8 PINGAUD, Bernard. La antinovela: sospecha, liquidación o búsqueda. Buenos Aires: C. Pérez, c1968.

9 QUEIRÓS, Bartolomeu Campos. Leitura e literatura. In: SIMPÓSIO NACIONAL DE LEITURA, Rio de Janeiro, 1994. Leitura, saber e cidadania. Rio de Janeiro: Fundação Biblioteca Nacional,1994. p.145-149. 